\title{
Las organizaciones inteligentes son organizaciones que saben de complejidad
}

\author{
Dr. Carlos Eduardo Maldonado \\ Facultad de Medicina \\ Universidad El Bosque (Colombia) \\ maldonado.carlos@unbosque.edu.co \\ maldonado.carloseduardo@gmail.com ORCID: \\ http://orcid.org/0000-0002-9262-8879
}

Recepción:18/05/2021 Aceptación:15/06/2022

\section{Resumen}

El institucionalismo y el institucionalismo constituyen manifiestos signos de una profunda crisis sistémica y sistemática; institucionalismo y neoinstitucionalismo político, económico, sociológico y otros. Dicho de manera puntual, las instituciones, de cualquier tipo, corte, color o matiz, son entes autorreferenciales: sólo saben de sí mismas, y sólo se quieren a sí mismas. La autorreferencialidad es la expresión abstracta de un craso error lógico: la tautología. A su vez, un error lógico no es otra cosa que una equivocación en una forma de vida. Precisamente las instituciones han dado en definirse a sí mismas en términos de Misión, Visión, Objetivos, Estrategia, Liderazgo, Himno, Bandera y otros artilugios. Como ya lo advirtiera muy tempranamente un sociólogo (Coser, 1999), las instituciones son voraces.

La crisis de las instituciones ha conducido a toda una serie de estrategias ingenieriles consistentes en observarse a sí mismas de tanto en tanto, a mejorar y corregir lo que sea necesario, y si es preciso, en algunas ocasiones a reinventarse por completo. El simple surgimiento del institucionalismo de cualquier índole es la señal de un profundo y estructural malestar en la economía, la sociedad, la cultura. Frente a este estado de cosas, este artículo postula que, semánticamente, debemos volver de las instituciones a las organizaciones, lo cual comporta un giro radical que pone inmediatamente ante la mirada la importancia y la necesidad de los rasgos distintivos de los fenómenos de complejidad creciente. La tesis de este artículo es que las organizaciones pueden y deben ser v ostas como sistemas vivos o bien como sistemas que exhiben vida, lo cual, en absoluto, puede ser dicho, ni siquiera en un sentido metafórico, con respecta a las instituciones. Instituciones o corporaciones, lo mismo da.

Pues bien, una organización inteligente es aquella que sabe de complejidad. Tal es el argumento central de este artículo. Este argumento implica un cambio de ciento ochenta grados de un modelo físico o fisicalista a uno de corte biológico o ecológico en la comprensión de las organizaciones, y por derivación, del Estado y todos los aparatos y sistemas organizativos en el sentido más amplio e incluyente de la palabra. 
Las bases mediante las cuales se fundamenta la tesis de este trabajo son cuatro. En primer lugar, se expone y se justifica el giro de la física a la biología en la comprensión de las organizaciones. De manera clásica, los temas de gestión y de administración en toda la línea de la palabra son, por así decirlo, hijos putativos de la física y la ingeniería clásicas. Se entiende perfectamente al estudiar a clásicos como Forrester, Taylor, Fayol, Ford, y demás. El lenguaje que constituye y permea al mismo tiempo a la gestión y la administración, lato sensu, es el de estructuras, procesos, lineamientos, recursos, energía, insumos, y demás. El segundo basamento plantea que, y justifica, cuáles son las características de las organizaciones (y no ya de las instituciones). Una mirada a la biología y la ecología se impone, campos atávicamente ajenos a la economía y la administración. Precisamente por ello, el tercer paso pone de manifiesto que, y por qué, las ciencias económicas, dicho en general, deben poder saber de vida, algo sobre lo cual, de manera tradicional ha estado ausente de sus preocupaciones. Al fin y al cabo, el modelo de este grupo de ciencias ha sido siempre distintivamente antropológico. Seguidamente, el cuarto aspecto sobre el que se funda la tesis señalada tiene que ver con el contexto actual, en el que abundan los datos y la información, lo cual contribuye a una transformación de los modos en que se han venido considerando las estructuras organizativas. Al final se extraen algunas conclusiones.

Este artículo expone que las ciencias de la complejidad, en tanto que son ciencias de la vida (Maldonado, 2021) sirven idóneamente como hilo conductor para una mirada compleja de las organizaciones. Una mirada semejante significa, dicho puntualmente, dos cosas: primero, que las organizaciones complejas son organizaciones inteligentes, y segundo, que una organización inteligente es aquella que ve vida y sabe de vida. Dicho lo anterior, debe quedar claro que en este trabajo no nos interesan para nada las instituciones. Las referencias a las mismas son simplemente indicativas y como forma de contraste. Todo el énfasis recae en lo que ampliamente es lo menos considerado: las organizaciones, que son sistemas de vida.

\section{De la física a la biología en la compren- sión de las organizaciones}

De acuerdo con la clasificación de las ciencias y disciplinas de la Unesco (2004), la economía, la administración y la contaduría no forman parte de las ciencias sociales -ni siquiera de las ciencias sociales aplicadas-; más propiamente, constituyen una unidad propia, justamente las ciencias económicas, contables y administrativas. Pues bien, estas son, prima facie las encargadas de las comprensiones y las gestiones de las organizaciones en toda la línea de la palabra. Este artículo interpela, por tanto, inmediatamente y de cara a cara a las ciencias económicas - política fiscal y hacienda pública, econometría, contabilidad, economía del cambio tecnológico, organización industrial y políticas gubernamentales, economía internacional, organización y dirección de empresas, economías sectoriales-, y consiguientemente, al conjunto ampliado y variado de las ciencias sociales. Al fin y al cabo, vivimos un mundo de organizaciones y es imposible existir por fuera de algún tipo de organización -la familia, la iglesia, el partido, el club, y demás-.

Originariamente, el término "organización" fue introducido por primera vez en 1802 por Lamarck a fin de establecer un criterio de distinción entre los sistemas vivos y los no-vivos. Así, "organización" sirve para comprender que estamos hablando de sistemas vivos; en una palabra, el mundo abiótico no sabe de organización. Sin embargo, el término fue genéricamente usado por parte de la administración, y con ella de las ciencias y disciplinas afines para designar en general: empresa, sistema estructurado -ejército, policía, iglesia- y, ulteriormente, por parte de la sociología para hablar de las "organizaciones de la sociedad civil, por ejemplo. En el ínterin, se introdujo, subrepticiamente, la "institución". El esquema No. 1 presenta la forma dominante como se ha entendido a las organizaciones, a partir de un modelo determinantemente fisicalista e ingenieril -en el sentido clásico de la palabra-. Al mismo tiempo, el esquema sirve para mostrar los cambios que se están produciendo y que permiten dirigir la mirada hacia la complejidad.

\section{Esquema No. 1: Flecha de complejización de bienes y servicios a conocimiento}

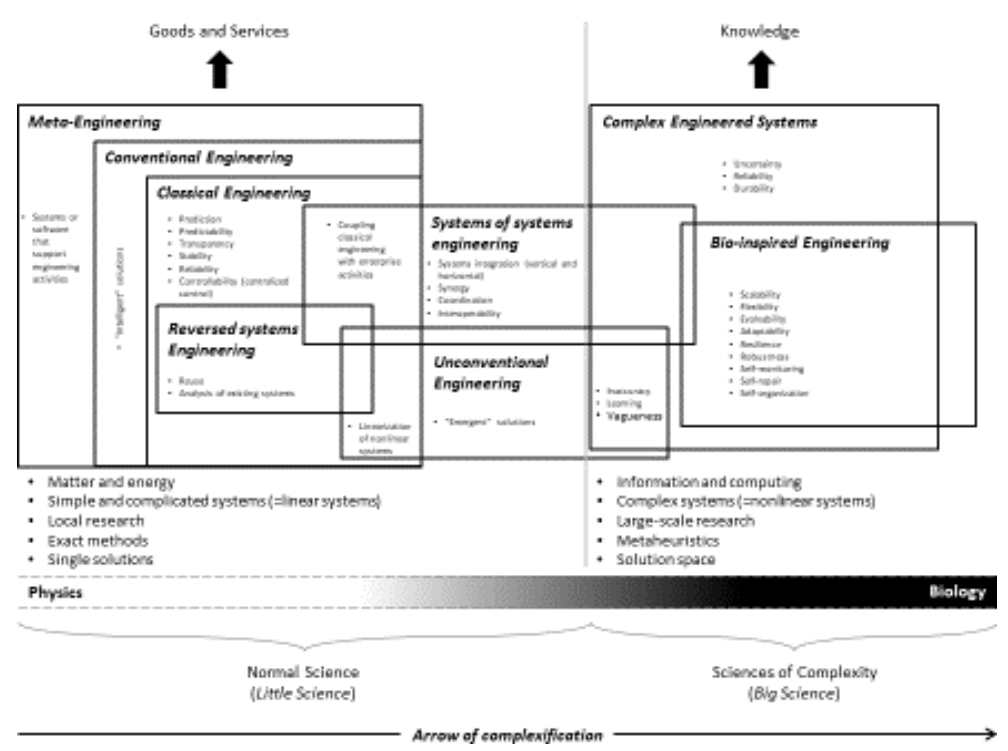

Fuente: Maldonado, Gómez (2015) 
El esquema No. 1 tiene varias líneas de lectura. Se trata de tránsito de la ciencia normal hacia la complejidad, y del desplazamiento también del interés, moderno, centrado en bienes y servicios, hacia la focalización en conocimiento. El hilo conductor es la ingeniería pero el esquema sirve, absolutamente, para las ciencias económicas y administrativas, cuyo fundamento, tácito, es justamente la física clásica y la ingeniería, como ya queda señalado. En efecto, mientras que en el pasado, y en el estado normal -en el sentido kuhniano de la palabra- el énfasis se pone el trabajo con materia y energía, el trabajo con sistemas simples y complicados, la investigación local y la búsqueda de soluciones particulares a los problemas, existe una tendencia en la investigación de punta, a trabajar con modelamiento y simulación, sistemas complejos, investigación de gran escala, metaheurísticas y espacios de solución. Pues bien, De manera significativo, asistimos a la metamorfosis de la ingeniería clásica, sus temas, su semántica, sus ejes y problemas, ulteriormente hacia ingenierar -valga el neologismo- sistemas ingenierados de manera compleja (complex ingenereed systems), que es la expresión empleada para designar la forma como se articulan gestionan, y se crean sistemas complejos, en toda la línea de la palabra. (Una traducción adecuada es: ingeniería de sistemas complejos; sin embargo, la expresión se presta para confundirla con otros tipos de ingeniería, digamos: civil, de alimentos, biomédica, electrónica y demás. La ingeniería de sistemas complejos "ingenieriza" -esto es, diseña, programa, gestiona- sistemas complejos, de forma no lineal, mecánica o mecanicista y con base en la física clásica como modelo o estructura mental).

De manera precisa, una comprensión fundada en la física y la ingeniería -las cuales, de manera clásica sólo saben de cuerpos y fenómenos inanes-, pivota en torno a conceptos como mecanismos, máquinas, estructuras rígidas o firmes o estables, eficiencia, eficacia, maximización, optimización y otros semejantes y próximos. En contraste, el énfasis en sistemas vivos sitúa en el foco conceptos y fenómenos tales como organismos vivos, vida, ecosistemas, metabolización, homeostasis, desarrollo, evolución y otros afines.

La dificultad enorme para una comprensión de las organizaciones como tales, estriba en el hecho de que carecemos, hasta la fecha, de una teoría (general) de las organizaciones. En biología tanto como en ciencias sociales y humanas, en ciencias económicas y administrativas, tanto como en el marco de la ecología. La principal razón radica en el hecho de que existen tres clases generales de sistemas sociales, así: los sistemas sociales naturales, los sistemas sociales humanos, y los sistemas sociales artificiales.
Ahora bien, en un hipotético caso, en el mejor de los casos habría tres teorías para cada uno de los sistemas sociales (la verdad es que en cada caso se cuentan numerosos tipos de teorías, de toda índole). Una teoría -general o unificada- de las organizaciones debería implicar, atravesar o comprender a los sistemas sociales naturales, humanos y artificiales. Esta idea permanece como una tarea por cumplir.

Las característica o ejes centrales de las organizaciones en la mirada mecanicista se concentra en predicción, predictibilidad, transparencia, estabilidad, confiabilidad, control centralizado. Basta una mirada a las estructuras de cualquier organización (estándar: iglesia, ministerio, empresa, corporación, ejército, organización deportiva y muchas otras) para comprobar que tales son sus características y ejes centrales. Por extensión, cabe pensar, asimismo, en temas como el reempleo (de materiales) o el análisis de sistemas existentes -por ejemplo, el estudio de casos-, como una ampliación y fortalecimiento, al mismo tiempo, de los rasgos o atributos señalados. Todo ello conduce a adoptar acciones y estructuras mentales como linealización, lineamientos y otros semejantes, todo lo cual sencillamente linealiza fenómenos o comportamientos no-lineales. La atmósfera de sistemas semejantes de organización es el control: interno, por parte de los trabajadores y demás; b) externos en el sentido del seguimiento de organizaciones semejantes. Toda la economía y administración clásicas y normales lo son del control.

Pues bien, un corrimiento de izquierda a derecha en el esquema No. 1 pone en evidencia que, de manera gradual, por así decirlo, suceden la aparición de soluciones emergentes y el aprendizaje de aspectos como la vaguedad, la imprecisión y el aprendizaje. Cuando ello sucede, mucho más que una transición, tiene lugar un cambio estructural que tanto da origen como que es el resultado del aprendizaje de la existencia de fenómenos, dinámicas, comportamientos y sistemas no-lineales - que no pueden, en manera alguna, ser linealizados-. En la vida de los ecosistemas de toda clase tienen lugar la aparición de atributos semejantes. La incertidumbre o la indeterminación constituye un rasgo sobresaliente fundamental de fenómenos complejos.

Así las cosas, los ejes en torno a los cuales pivotan las organizaciones ya no son precisamente los de bines y servicios -un concepto que, históricamente, pertenece en rigor a los años 1970s-; que era cuando, sectores muy sensibles para la vida de la sociedad, como la salud y la educación todavía eran designados y co0mrpendidos como pertenecientes al sector "servicios". Por el contrario, asistimos a la emergencia de la información, el conocimiento y el capital relacional como los 
tres rasgos distintivos de una nueva fase en la vida de la sociedad y, consiguientemente, los tres rasgos de lo que, en propiedad, cabe designar como organizaciones inteligentes. Hoy por hoy, para continuar con los dos ejemplos mencionados, la salud y la educación forman parte del sector conocimiento; no ya, en absoluto, del sector servicios. La semántica cambia por completo (por ejemplo, "cliente", "usuario" y otros semejantes simplemente resultan vacíos).

Cultural, social, epocalmente hemos comenzado a hacer un aprendizaje sin igual en toda la historia de la humanidad occidental, a saber: hemos descubierto la existencia de la vida o los sistemas vivos - un acontecimiento que, si bien tiene algunos antecedentes, apenas sucede plenamente a finales del siglo $X X$ y comienzos del siglo XXI-. Esta es quizás la más grande revolución mental y relacional que haya tenido lugar desde la invención de la estructura y la agricultura, en ese momento en el que el Neolítico se separa del Paleolítico. Una economía, administración, finanzas, sistemas contables y demás que surgieron antes del descubrimiento de la vida en general, marcados por una estructura mental mecanicista y reduccionista resulta inviable, e incluso peligrosa frente a los nuevos retos, desafíos, posibilidades y fenómenos alrededor del mundo. Sin ambages, es preciso abandonar la semántica y todo lo que ella comporta del institucionalismo y el neoinstitucionalismo y aprender de vida. Algunos de los ejes que emergen entonces, ante la mirada sensible, son: resiliencia, robustez, flexibilidad, autorreparación, automonitoreo y, muy sensible: autoorganización.

Así las cosas, planteamos abierta y directamente la necesidad de un giro de las organizaciones en el marco, en la semántica y en la atmósfera del aprendizaje de lo que comportan los sistemas vivos. La más inmediata de las puertas de acceso consiste en el aprendizaje de lo que son y hacen los sistemas vivos.

\section{Características de las organizaciones (en marcado contraste con las institucio- nes)}

Mientras que una institución es una estructura mecánica de procesos y lineamientos que solo sabe de fenómenos inanes -eficiencia, eficacia, ganancias, y demás-, una organización sabe de vida en toda la extensión de la palabra. Las instituciones convierten a sus componentes en medios para su propia perdurabilidad. Las organizaciones, por el contrario, saben que son medios o instrumentos para que sus componentes puedan desarrollarse y afirmarse en todo el sentido de la palabra. Dicho de modo genérico, los sistemas vivos nacen, crecen, se desarrollan, se enferman, se reproducen, en ocasionan se atrofian, aprenden, se adaptan, tienen procesos metabólicos, saben de homeostasis, y otras características próximas y semejantes. Son tres los grandes ejes articuladores que permiten entender lo que son y lo que hacen los sistemas vivos; estos son la biología, la ecología y las medicina y las ciencias de la salud.

Pues bien, quisiera decirlo de manera franca y directa: las organizaciones son sistemas vivos, exhiben vida o se comportan como sistemas vivos. Si esto es verdad, entonces una mirada a las organizaciones requiere, por así decirlo, una mirada, y un aprendizaje de, complejidad; muy específicamente, de las ciencias de la complejidad. Al fin y al cabo, el fenómeno de máxima complejidad conocida son los sistemas vivos en general. Dicho escuetamente, la economía, los sistemas de gestión y todo lo que ellos comportan deben poder saber de vida y ver vida, que es lo que permanece ampliamente ausente en los marcos de la economía y la administración en el sentido amplio pero fuerte de la palabra. Ellas sólo saben de cosas como fidelización del cliente, crecimiento económico, consumo, segmentación del mercado, misión y visión y otros artilugios semejantes. Nada ni próximo ni semejante a vida.

Dicho de manera rigurosa, las organizaciones existen en nichos ecológicos y en sistema ecológicos, todo lo cual es inmensamente más y muy diferente a la simple "cadena de valor". Es imperativo que la gestión de las organizaciones -cualesquiera sean su índole, naturaleza o finalidad-, aprendan de ecología.

Pues bien, el principal problema ecológico hoy en día es la gestión de la naturaleza; o mejor aún, la gestión de la sociedad la economía y la política de cara a la naturaleza. Instancias tan básicas como los diferentes informes al Club de Roma, los Objetivos del DesarroIlo Sostenible o la Carta de la Tierra -para mencionar las que son quizás, diferentes entre sí, las tres más importantes y conocidas iniciativas relativas a la naturaleza en el marco de las sociedades, las empresas y los gobiernos-. Los diagnósticos son amplios, sólidos y suficientemente conocidos, y los títulos genéricos, en orden de complejidad creciente son: el calentamiento global, el cambio climático, la crisis climática -etapa en la que nos encontramos actualmente-, y la catástrofe climática. La expresión puntual en la que se resumen estos cuatro títulos es el tema de los límites planetarios del Instituto Stockohlm (https://www.stockholmresilience.org/research/planetary-boundaries/ the-nine-planetary-boundaries.html). Desde el Foro Mundial de Davos, pasando por numeroso Tanques de 
Pensamiento, gobiernos, centros e institutos de investigación y universidades y empresas, el tema ha sido amplia, sólida y suficientemente reconocido y puesto sobre la mesa, a plena luz del día. La gestión de los asuntos humanos -en toda la línea de la palabra-, debe poder saber de naturaleza, de vida, de salud, o de la biosfera - cuatro expresiones distintas para señalar en sola y misma dirección.

Así las cosas, pensar las organizaciones comporta adoptar una estructura de mente ecológica o, lo que es equivalente, saber de biología, de ciencias de la salud y de ciencias de la complejidad. Un reto formidable para el grupo de las ciencias económicas cuando se las ve desde los ojos del pasado. Dicho, aquí, por última vez, se trata de abandonar las semánticas, prácticas y estructura que se definen a partir de liderazgo, estrategia, misión, visión, objetivos, himno, bandera, balance económico, balance tecnológico y demás, en favor de reconocer abierta y frontalmente: la sensibilidad ante las condiciones iniciales, de suerte que muy pequeños cambios pueden generar consecuencias de largo alcance totalmente impredecibles; flexibilidad, particularmente en tiempos y contextos marcados por inestabilidades, turbulencias, fluctuaciones y perturbaciones; y, muy particularmente, el que quizás es el rasgo más importante de todos, la capacidad de aprendizaje.

Una observación se impone aquí. Desde el punto de vista biológico, los organismos y las especies que no aprenden son justamente aquellas que se han especializado y que, por consiguientemente, tienen una muy baja o nula capacidad de adaptación. El aprendizaje es la conditio sine qua non para la adaptación; o bien, inversamente, la adaptación es el resultado del aprendizaje. Pues bien, aquellos organismos y especies que no aprenden muy pronto se vuelven endémicos, entran en peligros de extinción y finalmente terminan por extinguirse. Sorpresivamente, son numerosos los organismos y las especies en la naturaleza que no aprenden, a las que les resulta difícil adaptarse y terminan extinguiéndose. Asistimos, hoy en día a la sexta extinción masiva en la historia de la biosfera, una historia que, en términos de vida abarca cerca de 3800 millones de años.

Aquello que sucede en la naturaleza en este plano no es muy distinto a lo que acontece en la sociedad o en la cultura. Hay individuos que no aprenden, hay grupos que no aprenden, hay empresas y organizaciones iglesias, ejércitos, equipos deportivos, y demás- que no aprenden, hay incluso sociedad, pueblos y ultras y, en el límite, civilizaciones enteras que no aprenden. El resultado es una enorme mortandad, análogamente a lo que tiene lugar en la naturaleza. La cultura y la historia están hechas sobre cientos, miles, millones de casos, según el caso, que sencillamente no lograron aprender y adaptarse.

Una organización inteligente es, sin más ni más, aqueIla que aprende; y sólo los sistemas vivos que logran adaptarse son aquellos que aprenden; como sea (el aprendizaje no es, en absoluto, un proceso mecánico, fácil, garantizado, lineal y automático; existe un costo termodinámico en el aprendizaje; y por consiguiente, en la adaptación).

Pues bien, así las cosas, la expresión más inmediata y evidente de la capacidad de aprendizaje por parte de una organización consiste en la expresión de su topología; dicho en el lenguaje clásico, de su estructura organizacional, justamente. De manera atávica, las organizaciones se han estructurado jerárquica o verticalmente; desde los gobiernos y los ejércitos hasta la Academia, el Liceo, la Stoa y la Universitas; desde las iglesias hasta las empresas y corporaciones; desde la administración pública en todas sus escalas, en fin, la organización del conocimiento en sentido amplio y las organizaciones del mundo; específicamente en Occidente. En verdad, la concepción tradicional sobre las formas de organización en occidental ha sido distintivamente jerárquica, piramidal, centralizada. Es tal el exabrupto que, en esta concepción específicamente antropológica y antropomórfica del mundo y la realidad, erróneamente los seres humanos "vieron" cosas como un rey león, una reina abaje, una reina de las hormigas y cosas semejantes. En la naturaleza: a) no existen las jerarquías; o bien, b) cuando existen son perfectamente episódicas y pasajeras. La naturaleza se organiza en términos de relaciones no jerárquicas, en paralelo, distribuidas, difusas, no-locales, multinivel. Las ciencias económicas nada saben al respecto; ciertamente no en su forma normal de existencia y desenvolvimiento.

Una organización inteligente es aquella que reconoce que la topología de árbol, como se denomina específicamente, en el ámbito de las matemáticas en general, y de la complejidad en particular, resulta hoy por hoy arcaica. La célula, esto es, la unidad básica de la vida, es, por el contrario, una forma de organizaciones esencialmente móvil, cambiante y abierta, jamás cerrada (como lo son las instituciones). El esquema No. 2 ilustra diferentes topologías de red. 
Esquema No. 2: Topologías básicas de red

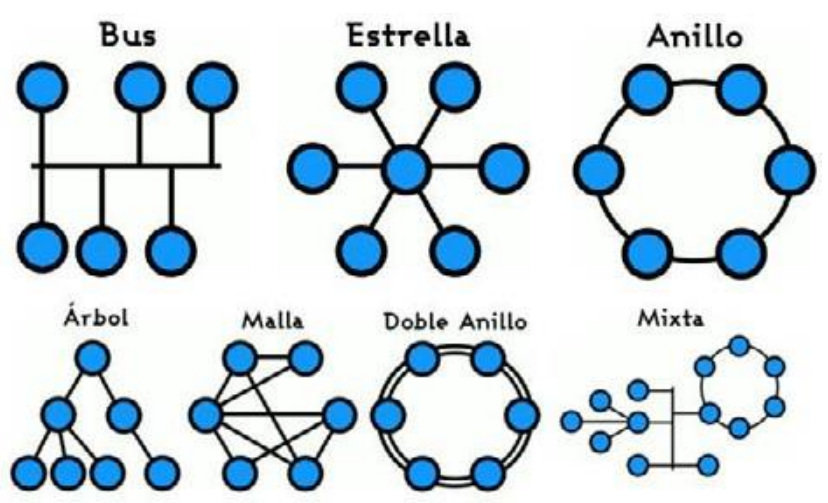

Fuente: Tomado de internet (pública)

El estudio de las estructuras organizativas se denomina en matemáticas: topología. La topología, que tiene ciertamente algunos antecedentes en la historia, nace particularmente en 1964 gracias a los trabajos de S. Smale. El tema de trabajo en topología -que es una de las áreas de las matemáticas de la complejidad y técnicamente se denomina o bien como matemáticas de sistemas discretos, o bien como matemáticas combinatorias-, consiste en considerar si una estructura determinada puede cambiar o no y por qué en otra, a condición de que en el cambio no suceda ninguna ruptura. Una mirada atenta al esquema No. 2 permite entender mejor esta idea.

La topología de árbol expresa la forma clásica como se han estructurado las organizaciones en la historia de Occidente. Pues bien, no es necesario que una organización se reduzca a dicha topología (Mezza-García, Maldonado, 2015). Si necesidad de entrar en las debilidades de una topología de árbol, el punto central aquí consiste en observar: a) que existen y son posibles otras topologías; b) que hay topologías de red mucho más robustas que la topología de red. Por consiguiente, cabe legítimamente la pregunta acerca de la posibilidad de transformación de una topología de árbol, en, digamos, de mala o de doble anillo. En tiempos de inestabilidad y turbulencias la pregunta por el panorama de las topologías de red resulta enteramente razonable. Una organización que aprende es aquella que logra entender que su estructura no tiene por qué ser eterna y que puede sufrir modificaciones. En biología, el capítulo que estudia las transformaciones estructurales es la morfología, y dichas transformaciones se designan propiamente como metamorfosis. La naturaleza sabe de numerosas especies que tienen metamorfosis, e incluso de algunas que tienen en el transcurso de su vida hasta cuatro metamorfosis, como las anguilas (Cooke, 2019).
La transformación de una estructura organizativa -u orgánica- es el resultado de proceso metabólicos. En economías en crisis, en gobiernos con alta o total ilegitimidad -nacional o por parte de la comunidad internacional-, en contextos de corrupción, inequidad o violencia en cualquier de sus formas, notablementeremite la mirada a procesos de metabolización. (hoy por hoy, como resultado de numerosos estilos de vida enfermizos, emergen alrededor del mundo serias enfermedades metabólicas, como la obesidad, el sobrepeso, la anorexia, y muchas otras. Las personas, según parece, se han olvidado de saber vivir o de aprender a vivir bien. Al final volveremos sobre esta idea, en las conclusiones).

Dicho de manera puntual: una organización es una forma sana de estructuración de procesos que sabe metabolizar y por tanto, tiene una homeostasis que favorece el aprendizaje, la vida y la adaptación. La homeostasis hace referencia a todas aquellas características, orgánicas, mentales y de medioambiente que contribuyen a sostener o a mantener a un organismo en condiciones de salud y desarrollo. Una expresión o traducción filosófica debida a Spinoza para designar la homeostasis es el conatus, que es la pulsión del organismo para mantenerse y hacerse posible.

Podemos sintetizar la transición, por así decirlo, de la gestión de las organizaciones -gestión económica, política, administrativa-, de una concepción y práctica mecanicista a una organicista en los siguientes términos: asistimos del giro del capitalismo industrial a la sociedad de la información, del capitalismo posindustrial a la sociedad del conocimiento, y del capitalismo informacional a la sociedad de redes. A una mirada sensible no escapa el significado de estos movimientos o cambios.

De manera puntual, a partir de lo anterior, cabe señalar que actualmente, en el contexto señalado, en los Consejos Directivos de las grandes empresas, corporaciones y universidades, además de los miembros de logística, seguridad, el aparato legal o jurídico, el administrativo, el financiero, el presidente y demás, adicionalmente, participa activamente un hacker. La idea elemental consiste en que el hacker: a) es el encargado -él y/o su equipo- de evitar justamente el hackeo a la empresa o el tipo de organización de que se trata, o bien, b) trabaja precisamente en el hackeo que se considere necesario. Esta es una práctica común reciente no siempre expresamente reconocida; o bien maquillada a través de eufemismos como: el encargado tecnología", y otras expresiones parecidas. 


\section{La economía, la administración y las disciplinas afines deben poder saber de vida}

De manera atávica, las organizaciones no saben de vida; antes bien, saben de otras cosas que no expresan ni traducen vida; por ejemplo, símbolos, poder, imagen corporativa o institucional, crecimiento, expansión, eficiencia, eficacia, punto de equilibrio de tal o cual tipo, y otras preocupaciones semejantes. La expresión, consciente o inconsciente del institucionalismo y el neoinstitucionalismo es simple y sencillamente la condensación de que, de suyo, las organizaciones no saben de vida; y entonces, manifiestamente no son organizaciones, sino instancias ingenieriles de control -de mercado, de crecimiento, de seguimiento de la competencia, y demás-.

Subrayemos esta idea: debe ser posible comprender que las organizaciones son sistemas vivos, que lo que sucede en ellas es vida y que, idealmente, exhiben vida. La manera más ingenua y desprevenida de decirlo es que se componen de personas, con todo y sus biografías, sus familias, sus círculos sociales y sus avatares existenciales; lo cual, en absoluto, es poco; todo lo contrario.

Cuando no son ya los bienes y servicios, sino el conocimiento lo que define a una organización -independiente de su actividad, finalidad, origen o fines-, sino el conocimiento, emergen entonces una serie de rasgos que bien marcan un fuerte contraste con el pasado. Se trata del know-how, la importancia de la experiencia, el reconocimiento acerca del carácter vital de la capacidad de improvisación, la creatividad, el sentido crítico en todas las instancias, espacios y modos, la autoobservación, en fin, la observación de los ecosistemas, próximos y lejanos. Veamos.

El principal asset, para emplear un término de uso habitual en las organizaciones hoy en día, de una organización el know-how, pero éste no existe en abstracto, sino precisamente en los agentes componentes y articuladores de las organizaciones según diferentes niveles y modos. Un ejemplo puntual sirve de ejemplo. En la Universidad de Cambridge, en Inglaterra ${ }^{1}$ existe una oficina dedicada enteramente a la conservación y protección de los profesores. Como es sabido, las empresas, organizaciones, clubes deportivos y demás practican abiertamente el robo de cerebros, jugadores o empleados. De suerte que Cambridge creó una oficina dedicada a evitar el robo de sus profesores por parte de otras universidades o empresas. Así, tienen en cuanta las dificultades, las necesidades, las ofertas y toda clase expresión cotidiana que en el día a día tienen o pueden tener los profesores. La fenomenología al respecto es amplia: se trata de una oficina dedicada a ayudarles con los pagos de las cuotas de que se trate -telefonía celular, arrendamientos, automóviles-, el cuidado de bebés en el caso de las madres con nacimientos recientes, vicisitudes de tipo económico, en fín, desarrollo, estudios, y demás. Al fin y al cabo, Cambridge ha invertido tiempo, energías, dinero en la captación, formación o consecución de un profesor, y no puede permitirse que se pierda el tiempo, las energías, el dinero invertido. Una universidad se hace con profesores, punto. Existe un caso semejante en una universidad colombiana. La fenomenología podría ampliarse a otros espacios, ejemplos y tipos de organizaciones. Se trata, en una palabra, del reconocimiento del know-how, el cual no solamente es colectivo o genérico, sino también particular o personal. Esta es una organización inteligente.

La experiencia es un acumulado de tiempo, aprendizajes, ayudas y contribuciones, incluso de fidelidad o lealtad, si se quiere. Una organización inteligente de cualquier índole sabe del relevo generacional, trabaja en función suya, y precisamente por ello logra una armonía dinámica entre juventud y experiencia. La juventud marca la dirección entorno a la capacidad de improvisar, de arriesgar, de pensar de manera heterodoxa (out of the box) y, particularmente, del sentido crítico.

Dicho de manera puntual, lo que se desprende de lo anterior es el reconocimiento expreso de que conocimiento y vida son una sola y misma cosa, una idea que, originariamente, se debe a Maturana y Varela (cfr. El árbol del conocimiento), pero que ha sido también el tema de otros investigadores (Solé and Goodwin, 2000).

De consuno, una organización que sabe -como se aprecia- de vida, tiene la capacidad de pensar, literal y metafóricamente, en ecosistemas. Así las cosas, es posible superar el dualismo entre la dimensión humana del mundo y la escala natural de la realidad. Los mejores desarrollos de la ciencia en general, de la cultura en particular, y de la educación en toda la profundidad de la palabra apuntan exactamente en esta dirección. La perspectiva eminentemente antropocéntrica de las organizaciones se ve ampliada en una concepción naturalista que no elimina a aquella, sino que la incluye como un momento particular.

El reto de mayor calado que cabe imaginar desde cualquier punto de vista consiste en la creación, mantenimiento, gestión y desarrollo de organizaciones de tal manera que no perjudiquen a la naturaleza en ningún sentido de la palabra y, más adecuadamente, contribuyan, dicho negativamente, a evitar la catástrofe climática, y dicho positiva o afirmativamente, contri- 
buyan activamente a una conciencia ecológica de los integrantes de la organización, de la sociedad y de los hilos y redes en los que existe la organización en cuestión. Un desafío formidable.

Saber de vida equivale a integrar cualquier tipo de preocupación de corte antropológico en un marco inmensamente más amplio que lo comprende y lo hace posible: el marco de la biosfera, con todo y los niveles, escalas y particularidades intermedios que la componen; por ejemplo, los pisos climáticos, los microclimas, el cuidado de las aguas y el aire, y demás.

De manera significativa y puntual, una idea semejante atraviesa, medularmente por un cuestionamiento y rechazo de la obsolescencia programada, la más grave de todas las faltas del capitalismo industrial y posindustrial, y la más catastrófica de las prácticas cuando se habla de empresa, organización, economía y demás. Un amplio y sonoro silencio reina en los medios académicos, económicos, políticos y administrativos en toda la extensión de la palabra acerca de la obsolescencia programada. Como se aprecia, ver vida, hablar de vida y defender a la vida en general es arduo; se dice fácilmente, pero es extremadamente difícil de llevar a cabo en el día a día.

Ver vida y saber de vida es bastante más y muy diferente a saber únicamente de asuntos humanos, del ser humano, o de la sociedad y el Estado -que son las instancias o referencias normales de las ciencias económicas, contables y administrativas. El espectro de la vida abarca desde los extremófilos, pasando por la distinción entre células eucariotas y procariotas, los tres dominios de la vida -eukaria, arquea y bacteria- pasando por gérmenes, virus, hongos y parásitos, hasta llegar a las plantas, los animales, los seres humanos y terminando, en el otro extremo, con la inteligencia y la vida artificial. Como se aprecia sin dificultad, las ciencias económicas - modo Unesco- poco y nada saben de vida. Asistimos, en este plano y contexto, a una auténtica revolución en el modo de existencia y trabajo de este grupo de ciencias. No conozco muchos trabajos en esta dirección ${ }^{2}$.

2 Sin la menor duda, la mejor doble puerta de entrada a estas ideas la ofrecen Georgescu-Roegen (1996) y Passer (1996). Dicho esto, la bioeconomía tal y como la inauguran, independientemente, ambos autores, muy poco o nada tiene que ver con la bieconomía estándar, cooptada e institucionalizada del tipo: economías circulares, economías verdes, bioeconomía como el uso de tecnología verdes, y otras semejantes, casi todas perfectamente acordes a los Objetivos del Desarrollo Sostenible (ODS). La razón para esta distinción aquí radica en que, particularmente con Georgescu-Roegen, la bioeconomía lleva a cabo una sólida y radical crítica de la función de producción,
Dicho en una palabra, hoy por hoy es imposible hablar de organizaciones inteligentes sin que estas sepan de vida. Pues bien, la puerta de entrada, por así decirlo, de corte inter, trans o multidisciplinar para saber de vida son las ciencias de la complejidad.

Saber de vida comporta ocuparse de los sistemas vivos tal-y-como-los-conocemos tanto como tal-y-como-podrían-ser-posibles, una distinción de corte filosófico que introduce originariamente el padre de la vida artificial, Ch. Langton. La justificación de esta dúplice comprensión radica en el hecho mismo de que los sistemas vivos son esencialmente inacabados e incompletos, y a que, adicionalmente, emergen nuevos programas de investigación que buscan ampliar la ventana de la comprensión de la vida, tales como la exobiología, la astroquímica y la astrofísica, el programa Seti (Search for Extra-Terretrial Intelligence), la búsqueda de exoplanetas (actualmente se descubren alrededor de cincuenta planetas semanalmente), y el profundo cuestionamiento y ampliación del modelo estándar de la cosmología científica, la teoría inflacionaria del big-bang.

Sin embargo, en el contexto de la sociedad de la información y la sociedad del conocimiento, saber de la vida implica un reto aún mayor.

\section{Organizaciones en el contexto de la in- formación y el conocimiento}

En efecto, un panorama acerca de la complejidad de la comprensión de la vida sucede exactamente en el marco de la sociedad del conocimiento. El esquema No. 3 presenta este panorama. Pero antes, a fin de entenderlo adecuadamente, es preciso resaltar una cosa. Este texto aboga por una complejización de las organizaciones. Esta complejización va exactamente en la línea de que estas deben poder saber de vida y entonces gestionar todas sus acciones, planes y sentido en función del cuidado, la exaltación, el posibilitamiento, la dignficación de la vida en todo el sentido de la palabra. De manera puntual, a mayor complejización de las organizaciones, mejor podemos concebir la perdurabilidad de éstas. Esto es, evitar o prevenir la enorme mortandad de organizaciones -por ejemplo, de empresas-, que es, de acuerdo con la Academia Mundial de Administración,

\footnotetext{
algo que permanece totalmente ausente en el caso de las bioeconomías estilo Unión Europea y otras (cfr., entre muchos otros, Bayne et al., 2021; Hodson de Jaramillo, 2018). Pues bien, una economía -lato sensu; por tanto, algo igualmente verdadero para la administración y la contaduría-, que no lleve a cabo una crítica de la función de producción y, por consiguiente, una crítica de la economía política, es sencillamente inocua y nada sabe de vida ni de naturaleza.
} 
el más grave de los males que aquejan a toda clase de organizaciones (cfr. https://aom.org/). Volveré inmediatamente sobre esta idea.
Fuente: Maldonado (2021)

La más importante de todas las herramientas jamás desarrollada por los seres humanos es la Máquina de

\section{Esquema No. 3: La complejidad de la comprensión de la vida}

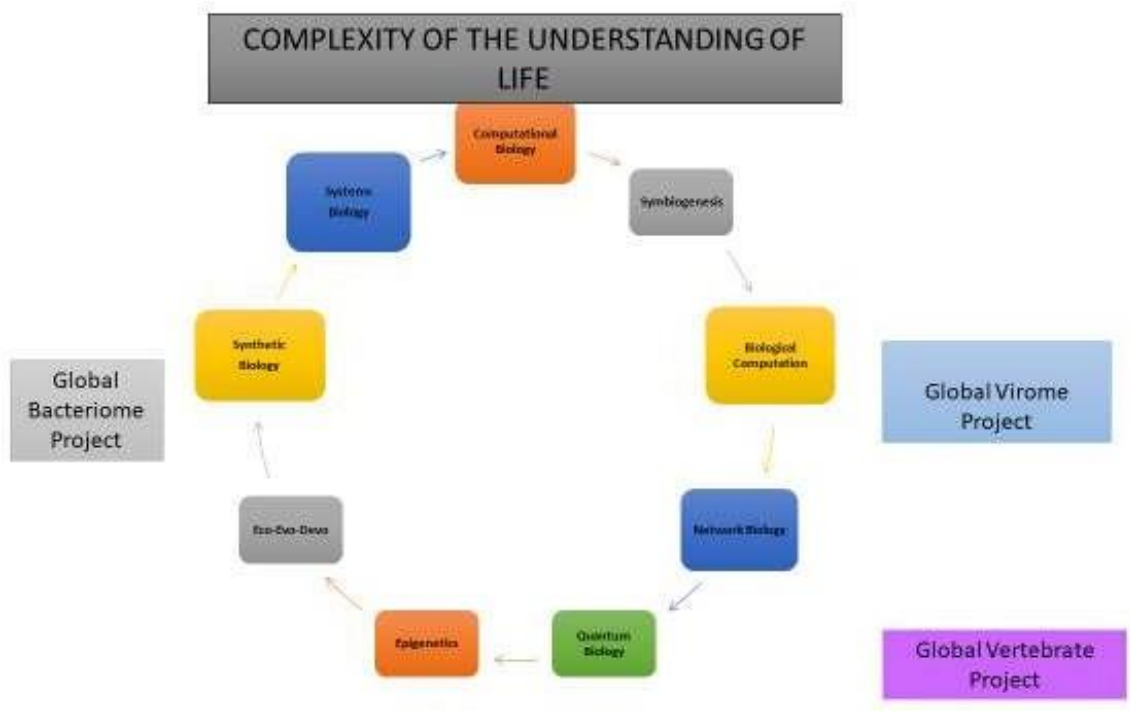

Turing (MT), usualmente conocida como el computador, y la computación. Justificar la importancia de la (MT) sería el objeto de otro trabajo, y ya va habiendo cada vez más conciencia acerca de su impronta cultural.

Pues bien, hoy por hoy, una comprensión de la vida está transversalmente atravesada por la importancia de la computación. El descubrimiento de la vida es un fenómeno concomitante con el desarrollo de la computación. En el esquema No. 3 -el orden no importa; adicionalmente, las flechas son caprichosas. Existen cruces entre varias de las esferas mencionadas. Aquí sólo daré una idea general- la biología computacional ocujpa un lugar destacado. De manera tradicional, los biólogos realizaban -y aún lo hacen- mucho trabajo de campo estudiando, por ejemplo, insectos, plantas, animales marinos y otros organismos y sistemas vivos, cuando no estaban en el laboratorio estudiando, por ejemplo, genética. Pues bien, el computador o la computación han venido a ampliar y profundizar enormemente el estudio de los sistemas vivos; no solamente el espectro se ha enriquecido enormemente -lo cual, de manera puntual puede ilustrarse con los tres proyectos mencionados por fuera del círculo, el Proyecto Bacterioma Global -que se abrió en 2007 y se cerró en 2013-, el Proyecto Viroma Global -abierto en 2017 y que se cerrará en el 2023-, y el Proyecto de Genomas de Vertebrados -abierto en el 2021 y cuya primera fase tomará entre seis y ocho meses, a la que le seguirán otras fases-. Más allá de los tecnicismos, las investi- gaciones en curso son posibles mediante el recurso a lenguajes de programación. La computación permea transversalmente a la biología -algo que otras ciencias y disciplinas no pueden afirmar con el mismo acento-.

Una de las aristas más importantes en la comprensión de la vida es la teoría de la simbiogénesis o endosimbiosis, formulada originariamente por L. Margulis en un artículo seminal de 1967. Contra la idea clásicamente darwininiana, los sistemas vivos: a) no aparecen, y b) no se sostienen y evolucionan con base en lucha y competencia -"mecanismos de selección natural"-, sino, además y fundamentalmente mediante aprendizaje recíproco, ayuda mutua, codependencia y coadaptación Así, la cooperación y la colaboración es la regla en la naturaleza, y no la lucha por devenir el organismo o la especie más aptos.

Estrechamente conectada con la biología computacional, la computación biológica constituye otra arista que pone en evidencia que no solamente la biología se favorece de la Máquina de Turing, sino, además, la propia computación aprende de e incorpora aspectos de la biología. Así, por ejemplo, se trata del desarrollo de memorias con base en proteínas o en ADN, la importancia de la biocomputación y la computación bioinspirada, el desarrollo de la computación paralela, emergente e incluso autoorganizativa. 
La biología de redes, fuertemente conectada con la biología de sistemas, se conecta con la teoría de la simbiogénesis en cuanto pone en evidencia que no existe un gen y que un gen no hace nada; antes bien, existen cadenas de genes, y son estas cadenas o redes, por ejemplo, las que configuran fenómenos tan importantes como salud, homeostasis, metabolización. En este mismo sentido, cabe hablar legítimamente de cadenas o redes de proteínas de lípidos o de redes neuronales, pero también, en el marco de los diferentes tipos de ecosistemas, cabe hablar de redes de sistemas vivos, como lo son, por ejemplo, las canopias en los bosques y selvas, y los procesos de codependencia y ayuda recíproca entre plantas de toda índole, incluidos los árboles.

No sin antecedentes que se remontan a los años 1930s, la biología cuántica puede decirse que nace en el año 2010 cuando orgánicamente se descubre que los sistemas vivos hunden sus raíces en fenómenos y comportamientos cuánticos pero que se expresan y actúan en un mundo clásico. Fenómenos como la magnetocepción, la fotosíntesis, la olfacción, la propia visión y la audición, para no mencionar adicionalmente, el funcionamiento del cerebro en aquellos organismos que lo tienen, son fenómenos específicamente cuánticos que suceden y expresan propiedades como no-localidad, tunelamiento, superposición, y otros atributos que ya la mecánica cuántica había estudiado, en sus fundamentos, en los años dorados de 1924-1927. La vida en general, cabe decir, es un fenómeno cuántico, que, sin embargo, los seres humanos observamos como si fuera un fenómeno clásico, esto es, regido por el principio de tercero excluido, el principio de no-contradicción y la identidad. Un ejemplo puntual: hay especies como las anguilas que en el curso de su existencia tienen cuatro metamorfosis, usualmente sabíamos de una; por ejemplo, la del gusano de seda en mariposa, o la del renacuajo en sapo o rana, por ejemplo. Los mejores desarrollos de la biología cuántica aún están por suceder. La epigenética, que encuentra sus orígenes en los trabajos pioneros de Waddington en 1942, nace, puede decirse hacia el año 2005, y consiste en el estudio de que los seres vivos no solamente heredan y trasmiten genes, sino también, experiencias. Para el año 2005 estaba establecido que este proceso de herencia y transmisión tenía lugar en hasta tres generaciones, pero para el año 2021 ha quedado establecido que la herencia y trasmisión de genes y experiencias tiene lugar hasta ocho generaciones; esto es, en términos humanos, más allá de un siglo. La epigenética ha sido verificada en plantas, animales y seres humanos. Los mecanismos mediante los cuales opera la epigenética son algo técnicos y pueden ser dejados aquí, temporalmente de lado. La idea fundamental consiste en poner expresamente a plena luz del día que no existen dos cosas: cultura y naturaleza, sino que ambas son una sola y misma cosa. Sin dudas, el más revolucionario de todos los descubrimientos sobre la vida en general.

Perfectamente conectado con la endosimbiosis y la epigenética, el enfoque eco-evo-devo consiste en la puesta en evidencia de que las tres dimensiones fundamentales para explicar a los sistemas vivos, la dimensión ecológica, la de la biología del desarrollo, y la perspectiva evolutiva o evolucionista, constituyen una férrea unidad. Es perfectamente imposible separar, ni siquiera analítica o epistemológicamente, la perspectiva individual, la colectiva o de especies y la inscripción de la importancia con los biomas, los ecosistemas, y en general con la biosfera. Dicho de manera puntual aunque quizás algo técnica, la explicación sobre la evolución de los sistemas vivos admite tanto la comprensión darwiniana -y neodarwiniana- como la lamarckiana. El enfoque eco-evo-devo emerge hacia finales del siglo $\mathrm{XX}$ y se despliega en diálogo con las otras aristas presentadas en el esquema No. 3.

La biología sintética constituye un programa de investigación reciente cuyos orígenes se remontan a la ingeniería genética, pero que su vez superan, y con mucho a ésta última. La biología sintética tiene dos perspectivas: la que se denomina como top-down, consistente en la creación de sangre artificial, de células artificiales y la manipulación de genes para crear tejidos y organismos nuevos, y la perspectiva bottom-up, que también trabaja en la creación de tejidos artificiales -sintéticos, justamente-, y cuya tarea central consiste en acelerar la evolución natural, la cual clásicamente era muy lenta y que tenía lugar verticalmente; esto es, de una generación a otra. La biología sintética permite entender que la evolución también sucede horizontalmente. Un descubrimiento importante y que abre vasos comunicativos con los proyectos mencionados por fuera del círculo en el esquema No. 3, consiste en la importancia del microbioma o la microbiota. La historia de la biología sintética no abarca, al día de hoy, más de veinte años, pero sus horizontes son promisorios. La tecnología Crispr -que permite escribir genes o sobre el genoma-, constituye la más reciente de las derivaciones de la biología sintética. Literalmente, estamos ad portas de crear vida nueva desde cero.

La biología de sistemas consiste en el estudio de redes y cadenas de procesos al interior de los organismos vivos, articulados, por ejemplo, en la metabolómica, la proteómica, la genómica, la fluxómica y otras más, todo lo cual no quiere significar otra cosa, sino que un organismo vivo es una fantástica y muy compleja red de redes. Dicho de manera puntual, el origen de la vida 
no puede ser explicado, en manera alguna de manera analítica, composicional y agregativa, sino por vía de síntesis; esto es, la vida nace ya compleja y va adquiriendo una complejidad reciente en cada nivel, en cada un nivel con otro, en fin, en una red con otra. Como se parecía, asistimos a un panorama novedoso y apasionante.

Pues bien, la idea de base consiste en el reconocimiento expreso de que en general debemos: a) poder ver; y b) saber de vida. De manera tradicional la inmensa mayoría de las gentes no ven vida y no saben de vida; antes bien, por culpa del pasado y de la cultura, ven sexo, dinero, mercancías, montañas, ríos o mares, objetos, edificios, monumentos, símbolos, poderes, límites, restricciones, pobreza, abismos, animales o plantas, armas y demás. La vida es un fenómeno alta y crecientemente contraintuitivo. El más apasionante de todos los descubrimientos jamás realizados.

\section{Conclusiones}

No es posible la vida de los seres humanos, por decir lo menos, por fuera de alguna organización; puede ser la familia, un círculo de amigos, la empresa, el colegio, la universidad, la iglesia, el partido, el club o cualesquiera otros. Contradictoria y sorpresivamente, sin embargo, de manera atávica, las organizaciones se han convertido -acaso, sin una mirada pesimista, desde siempre- en estructuras verticales, piramidales, jerárquicas y centralizadas; eso han sido las iglesias, los ejércitos, los sistemas de gobierno, las universidades y colegios, en fin, las empresas y corporaciones. Organizaciones regidas por leyes y reglas en las que estas, al cabo, han terminado por volverse en fines ("no es posible la vida por fuera de las leyes y normas", se dice). Al final del día, las organizaciones se transformaron en instituciones. Si en la naturaleza existe involución, en la historia de las sociedades sucede algo semejante.

Este texto ha argumentado en el sentido de que deben ser posibles -y efectivamente, las hay-, organizaciones inteligentes. Sin ambages, una organización inteligente es aquella que sabe de vida y comprende que todo lo que sucede alrededor suyo y en su interior sus procesos, dinámicas, comportamientos de vida - en toda la línea de la palabra. En este sentido, la lógica de este artículo se sitúa en el deber ser, con una advertencia: lo que hay en el mundo es una enorme mortandad de organizaciones, empresas y demás. Si una organización de cualquier índole quiere perdurar, debe ser inteligente, y entonces, claro, aprender; para ello, lo mejor que puede hacer es saber de vida, para lo cual la ecología, la biología, las ciencias dela vida y las ciencias de la complejidad constituyen referencias, por así decirlo, más que necesarias. Hoy por hoy, ya no es suficiente con saber de bienes y servicios en toda la línea de la palabra y con todo lo que ello implica. Además y fundamentalmente hay que saber de vida y conocimiento.

El mundo vive hoy una crisis sistémica y sistemática; esto es, en otras palabras, una serie de crisis que son de tal índole que unas inciden sobre otras y es imposible considerar o resolver alguna sin atender al mismo tiempo a otras, más inmediatas o indirectas. Los diagnósticos sobre la crisis son abundantes, variados y sólidos. Las ciencias económicas -debido justamente a la importancia de los procesos económicos-, lato sensu, tienen al mismo tiempo una responsabilidad y una culpa en la crisis actual y creciente del mundo y la naturaleza. Simple y llanamente, la crisis es el resultado de factores antropogénicos.

Todo parece indicar sin duda alguna que, dicho de manera genérica, las personas han olvidado a vivir bien; o algunas jamás lo aprendieron. Pues bien, lo mismo sucede con innumerables organizaciones, gobiernos y empresas, por decir lo menos. Vivir bien es el tema de un descubrimiento que el mundo en general realizó hacia comienzos del siglo XX precisamente en el estudio sobre las crisis. Los pueblos y culturas andinos y mesoamericanos aparecieron entonces como protagonistas de primera línea. Se trató y se trata, expresamente, de la importancia del suma qamaña, sumak kawsay -principalmente en Perú, Ecuador y Bolivia-, y el utz k'aslemal de los pueblos mayas, en Guatemala y México, principalmente-. En otras palabras, el tema se formula como el saber vivir, el vivir bien y la importancia y significado de llevar una vida plena.

En verdad, la mayoría -con optimismo, la casi totalidad de las instituciones- adolecen, hoy por hoy de enfermedades metabólicas. Las enfermedades o trastornos metabólicos son congénitos. Por ejemplo, la hipertensión, la obesidad, la arterioesclerosis, la demencia, el cáncer, el síndrome de ovario poliquístico, la diabetes, por ejemplo. Se trata del resultado de malos regímenes alimentarios, de vivir en entornos contaminantes y llenos de polución, en fin, de estilos de vida bastante poco saludables, como estrés (crónico), soledad, falta de afecto, y otros rasgos que es fácil identificar o adivinar, aquí.

Una enfermedad metabólica es el resultado de no saber vivir -por ejemplo, no saber alimentarse, respirar y otras actividades elementales perfectamente vitales-, que pueden heredarse (= epigenética) y que terminan siendo tanto enfermedades crónicas como agudas y complejas. La vida dejó de ser el centro de las acciones y decisiones -si alguna vez lo fue en la historia de Oc- 
cidente-, y otras cosas pasaron a convertirse en fines; notablemente: crecimiento económico, crecimiento de mercados, eficiencia y eficacia, ganancia, fidelización del cliente, competitividad y otros asuntos semejantes que constituyen la existencia normal de áreas como la economía, la administración y sus áreas y disciplinas componentes y articuladoras. Al final del día, la Iglesia y el Estado hicieron de sí mismo un fin, y todo lo demás fue reducido a medio o instrumento, para decirlo de manera sintética.

Pues bien, es hora de transformar estructuralmente las organizaciones (= topología). En otras palabras, se trata de cambiar al mundo cambiando las organizaciones. Para ello, debemos poder ver lo que consuetudinariamente ellas no ven y no saben: vida. Es más fácil de lo que parece.

\section{Referencias bibliográficas}

Bayne, K., Wreford, A., Edwards, P., Renwick, A., (2021). "Towarfs a bioeconomic vision for New Zeland - Unlocking barriers to enable new pathways and trajectories", en: New Biotech-nology, 60, pp. 138-145; doi: https://doi.org/1010166/j.nbt.2020.09.004

Cooke, L., (2019). La inesperada verdad sobre los animales. Barcelona: Anagrama

Coser, L. A., (1999). Las instituciones voraces. México, D. F.: F.C.E.

Durand, Th., and Dameron, S., (Eds.), (2008). The Future of Business Schools. Scenarios and Strategies for 2020. London: Palgrave Macmillan

Georgescu-Roegen, N., (1996). La ley de la entropía y el proceso económico. Madrid: Argentaria

Gilpin, D. R., Murphy, P. J., (2008). Crisis Management in a Complex World. Oxford: Oxford University Press
Hodson de Jaramillo, E., (2018). "Bioeconomía: el futuro sostenible", en: Rev. Acad. Colomb. Cienc. Ex. Fis. Nat., 42(164): 188-201, julio-septiembre; doi: http://dx.doi. org/10.18257/raccefyn.650

Maldonado, C. E., (2021a). Las ciencias de la complejidad son ciencias de la vida. Santiago de Chile: Ed. Trepen

Maldonado, C. E. (2021b). "Death and Complexity", en: Revista Latinoamericana de Bioética, vol.21(1), págs. 113-126, doi: https://doi.org/10.18359/rlbi.5376

Maldonado, C. E., Gómez-Cruz, N., (2015). "Biological Hypercomputation: A New Research Problem in Complexity Theory", en: Complexity, Vol. 20, Issue 4, págs. 8-18, ISSN 1099-0526; doi : https://doi.org/10.1002/cplx.21535

Mezza-García, N., Maldonado, C. E., (2015). "Crítica al control jerárquico de los regímenes políticos: complejidad y topología", en: Desafíos, (27-1), págs. 121-158, ISSN 0124-4035; ISSNE 2145-5112; doi: https://doi. org/10.12804/desafios27.01.2015.04

Michalewicz, Z., Schmidt, M., Michalewicz, M., Chiriac, C., (2007). Adaptive Business Intelligence. Springer Verlag

Passet, R., (1996). Principios de bioeconomía. Madrid: Argentaria Solé, R., and Goodwin, B., (2000). Signs of Life. How Complexity Pervades Biology. New York: Basic Books

Unesco, (2004). Clasificación Unesco de las áreas de ciencia y tecnología; disponible en: https://web.ua.es/ vrinvestigacio/documentos/documentacion/clasificacionunesco-de-las-areas.pdf, y también: https://www.epn.edu. ec/wp-content/uploads/2017/03/codigos_unesco.pdf 